\title{
RENDIMIENTO ACADÉMICO Y DESARROLLO HUMANO
}

\section{Por Hernán Felipe Prieto*}

Debo comenzar haciendo una necesaria confesión de ignorancia: No sé lo que es "Rendimiento Académico" y sí que menos lo que significa "Desarrollo Humano". Desde que se escriben con mayúsculas deben ser cosas importantes, más aún siempre las he escuchado, pronunciadas con suma gravedad, por lo tanto deben ser sumamente graves. Me avergüenzo y me arrepiento por no haberle preguntado a las personas que las pronunciaban y las escribían sobre lo que querían decir con ellas; pero, bastaba con imaginarme su rostro descompuesto de indignación ante el neófito que se permitía indagar sobre los cimientos mismos de su templo, para de inmediato, atemorizado contenerme. Además, es ya conocido mi hastío por las cosas y los seres graves. Soy un ¡Calvinista! Calvinista sí, pero de Italo Calvino, el exquisito escritor italiano ... .o para que no se ofendan los puristas, debo decir más bien, Calvinista, seguidor de Calvin, el de las tiras cómicas.

¿Qué hacer entonces ante este tema que me fue propuesto, que yo no escogí, sino que se medio por tarea de fin de año? Divertirme un poco. Divertirme, de "diversión" ,es decir: Di-versión. Busqué otra versión sobre esas palabras tan graves. A mi lado estaba Hobbes, no el filósofo inglés que escribió: "La única pasión de mi vida ha sido el miedo", sino el tigre que Calvin y yo tenemos para conjurar el miedo.

Miedo a los padres, a la escuela, etc. Hobbes me trajo el Diccionario de la Real Academia en su vieja edición de 1947 (me he resistido a comprar la actualizada porque aquella edición ha sido la compañera de mi vida y una nueva la juzgarían mis neuronas como apócrifa). Busqué allí la palabra "Rendimiento" y ¡oh sorpresa! Tenía cuatro acepciones:

1) Rendición, Fatiga, Cansancio, Descaecimiento de las fuerzas.

2) Sumisión, Subordinación, Humildad.

3) Obsequiosa expresión a la sujeción a la voluntad de otro en orden a servirla o complacerla.

4) Producto o utilidad que da una cosa.

Me pregunté entonces asustado: ¿A quién pretendíamos rendir, fatigar. cansar? No, no podía ser esto a lo que se referían los profesores... Entonces, ¿de quién queríamos su sumisión? Su subordinación, su humildad? No, no era posible que las sabias personas que hablaban del "Rendimiento Académico" quisieran de sus alumnos cosas como estas. Le pregunté a la tercera acepción, pero de inmediato la descarté: no era posible que tan buenas almas quisieran convertir a los alumnos en lacayos...

Me queda entonces la cuarta acepción, pero era todavía más molesta, había algo en mí que se resistía a aceptar lo que ya es común en los labios de la mayoría de los " educadores", que se preguntan con toda seriedad, con toda gravedad: “¿qué producto queremos sacar de nuestros estudiantes? Y todavía más, tercamente no quería hablar de los estudiantes como: "cosas".

\footnotetext{
* Profesor del Dpto. de E.F. de la UPN 
De pronto: una luz en el camino, el diccionario me decía que la palabra

rendimiento viene de rendir. Corrí entonces a la entrada rendir, con más sed de saber que la de un hombre arrojado al desierto del Sahara. Pero mi esperanza pronto se disolvió, tenía 12 acepciones! ¿A cuál de ellas se referían nuestros sabios profesores? Imposible...

1) Vencer, sujetar, obligar a las tropas, plazas o embarcaciones enemigas, etc., a que se entreguen.

2) Sujetar, someter una cosa al dominio de uno.

3) Dar a uno lo que le toca, o restituirle aquello que se le había desposeído.

4) Dar fruto o utilidad una cosa.

5) Cansar, fatigar, vencer (y daba un ejemplo: Se rindió de tanto trabajar).

6) Vomitar o volver la comida.

7) Junto con algunos nombres toma la significación del que se le añade. Ej. rendir gracias: agradecer, rendir obsequios: obsequiar.

8) Dar, entregar.

9) Mar. Tratándose de una bordada, de un crucero, un viaje, etc., terminarlo, Ilegar a su fin.

10) Mii. Entregar, hacer pasar una cosa al cuidado o vigilancia de otro, rendir la guardia.

11) Mil. hacer con ciertas cosas actos de sumisión y respeto, rendir el arma, la bandera.

12) Mar. Romperse o henderse un palo, mastelero o verga.

Imposible que fuera la primera, no creo que los profesores intentaran con su famoso rendimiento: vencer, sujetar, obligar. Si no era así, tampoco la segunda. La tercera tenía un dejo de violencia, de alienación, de alarde justiciero en el que el profesor parece que exigiera del alumno que le devolviera lo que le había dado, como si la enseñanza fuera un toma y daca con maquinita registradora incorporada:

"Te dí esto, súmale esto, agrégale esto, por lo tanto me debes esto, más esto y esto...", no, definitivamente no podía ser. La cuarta conectaba con su " homóloga" como dicen ahora, de las acepciones de rendimiento. La dejé para el final por si acaso... Cansar, fatigar , etc., ya estaba excluida.

La sexta me develé lo que ocultaba la tercera y mi sorpresa comenzó a trocarse en rabia. "Vomite lo que le dí-parecía decir mi hipotético profesor- escupa, escupa, para ver qué se comió"... Pero todavía quería creer en la buena fe de los profesores. Así que pasé a la séptima, donde aceptando violencias a los significados, la cosa quedaría algo así como este engendro:"Rendimiento Académico quiere decir Académico". Por esta vía todo parecía ir para largo... pero no tenía de qué preocuparme, me quedaban cuatro 
acepciones. Dar, entregar, repetían a su manera la tercera y la cuarta. La novena era demasiado marítima.

La décima y la décima primera.., las muy militares, me reforzaban en mis sospechas que comenzaban a crecer. Rendimiento Académico apoyado en las tres primeras acepciones de rendimiento y estas dos acepciones de rendir se conectaban de tan odiosa forma que, mostraban a los profesores como ejércitos de bárbaros que, vencida la ciudadela alumno- la obligaban a claudicar, a hincar sus rodillas y reconocer a sus vencedores... cosa que la última de las acepciones en su sentido marítimo no hacía más que confirmar.

¿Qué me quedaba entonces? Abrí mis oídos a las voces "humanitaristas" que me decían: "Usted está haciendo una lectura tendenciosa y sofista de lo que queremos decir. Cuando hablamos de Rendimiento Académico nos referimos a la cuarta acepción de Rendimiento y a la cuarta de rendir, sólo que no nos referimos al alumno como una cosa, sino como un ser humano que queremos moldear para su propio bien, para su Desarrollo Humano. Por eso hablamos de Rendimiento pero lo situamos en un contexto Humano, es decir Académico. Es decir que forzando las cosas nos remitimos también a la séptima acepción donde más que rendimiento lo que importa es que sea Académico.

Por los griegos sabía el respetable origen de Académico y de Academia. Pero los griegos parece ser que para tan respetables personas estaban más que muertos. Había una salida, la séptima acepción de Academia: Establecimiento en que se instruye a los que han de dedicarse a una carrera o profesión, y la tercera y cuarta de académico:

3) perteneciente o relativo a las academias, o propio y característico de ellas

4) Dícese delos estudios, diplomas o títulos que causan efectos legales...

Ellas me aclararon lo que los sabios querían decir. Tenía entonces algo así como "Instrucción con miras a un título que causa efectos legales". Ahí si no había vuelta de hoja, ¡Al fin había llegado al anhelado oasis! Por fin podía disponerme a comer tranquilamente los deliciosos dátiles de la Enseñanza Sagrada, y los ayudaría a pasar, no con el odioso nombre de "alumno vencido en juicio de asedio a su ciudadela", sino con el merecido título profesional que causaría el premio de los efectos legales para... el Mercado de Trabajo ... Hobbes saltó sobre el diccionario y patinando sobre él me despertó de mi sueño dogmático... no, no había tal oasis, sino el odioso "fata morgana" de mi alucinación, que ya, cansados mi camello ( mi diccionario) y yo, deseábamos, más que teníamos, nuestro oasis... Había que reemprender la marcha, pero, ¿por dónde?

Quise apoyarme en una palabra sacrosanta que venía persistentemente repitiéndose a lo largo de mis divagaciones: ENSEÑANZA. El diccionario bellamente no me remitía a la insípida "doceo" latina, sino a la sabrosa y también latina "insignare". ¿Por qué tuve que acudir al latín?

Me daba vergüenza pensar que nuestros profesores con la palabra Enseñanza quisieran significar algo parecido a las acepciones 2, 3, 4, 5 y 6 que traía mi diccionario:

2) Dar advertencia, ejemplo o escarmiento que sirve de experiencia y guía para obrar en lo sucesivo.

3) Indicar, dar señas de una cosa. 
4) Mostrar o exponer una cosa, para que sea vista o apreciada.

5) Dejar aparecer, dejar ver una cosa involuntariamente.

6) r. Acostumbrarse, habituarse a una cosa.

De la segunda, parece, que los "modernos" pedagogos apenas están saliendo, apenas se están limpiando, sobre todo por aquello del escarmiento para que aprendan los alumnos como Debe obrarse en lo sucesivo.

La tercera era muy insípida. La cuarta era demasiado "exhibicionista" para el gusto de tan graves profesores del Desarrollo Humano. Además había acabado de leer a Bordieu sobre el Gusto y ya tenía suficiente con ello para sentir miedo de la palabra "apreciación". Hay demasiado interés por que "apreciemos" ciertas cosas, como para que desconfiemos con sobrada razón de invitación de esa laya. La quinta era todo lo contrario de la tercera, demasiado sabrosa para el ascético gusto de los pedagogos, demasiado traviesa para ellos, pero no para un sofista como yo. Pero de lo que se trataba era de preguntarme qué pensaban ellos y no de lo que yo pensaba de ellos. La sexta sí que era peligrosa y odiosa, para ellos. Por lo tanto Tenía que ser la primera.

Pero aún en la primera,

1) "Instruir, doctrinar, amaestrar con reglas o preceptos", había problemas con "doctrinar" y sobre todo con "amaestrar". No, ¡Jamás nuestros pedagogos pretenderían decir tal cosa!

Quedaba, por sustracción, que Enseñar significaba instruir. Pero INSTRUIR, decía mi diccionario, significaba Enseñar!. Qué odioso círculo vicioso. Así que para salir de él, me dirigí al latín: Insignare. Por lo de "in" no había problema: preposición que por regla general equivale a "en”. Entonces Signare. Y ¡Ahí sí fue la debacle! ¡Era demasiado! Signare, de Signo en latín que quiere decir: marcar, señalar con un signo distintivo, sellar, acuñar, indicar. Igual que Signum: marca, señal. Ej: "pecori signum imprimere": marcar un rebaño.

Los monstruos de la razón de las tres primeras acepciones de rendimiento y las doce (más una familiar que mi viejo D. R. A. no trae - no sé si en las actuales ediciones se contempla- y queme parece tiene un origen culinario. Se dice "hacer rendir el vino" es decir: "agregarle agua para que rinda" de "rendir") saltaron sobre mí. Hobbes, sobra decirlo, se escondió debajo de la cama.

De manera que Signo y Signum significaban Marcar. Y no cualquier tipo de marcaje: "pecori signum imprimere" iQue terrible frase! Calvin al fin apareció diciéndome: No te lo dije? ¿Por qué crees que me resisto a ir a la escuela? ¿Porqué crees que le robo las tareas a Lisa? ¿Por qué crees que le tengo miedo a la maestra? ¿Por qué crees que tengo a Hobbes? Nietzsche detrás de Calvin apareció: "¿Fatuo, engreído - me dijo - me citas con qué suficiencia y sin embargo no te has detenido a rumiar lo que escribí en la Genealogía de la Moral?" Me la arrojó a la cara y terminó diciéndome: " O sales al patio a jugar con nosotros o te quedas ahí 'rindiendo' para ellos. Si haces lo segundo no te lamentes después, no protestes por la marca que te pondrán en el trasero, marca de fábrica, distintivo, sello, título de "pecoris" con efectos legales.. ." Hobbes salió tras Calvin y Nietzsche diciéndome: "Ven a jugar con nosotros. No a hacer deporte, porque en el deporte hay Rendimiento Deportivo. En cambio no se puede decir Rendimiento de Juego...". 
¿Cómo hacer mi tarea sin los tres?, ¿Cómo Rendir este informe sin los tres?

Tenía la tentación de hablar sobre mis miedos. Miedo a la palabra Pedagogo, que alguien definió perfectamente en su origen griego como "esclavo ilustrado de confianza". Miedo a la palabra Alumno que en Roma era el esclavo favorito del "pater familias". Miedo a la palabra Enseñanza que no es otra cosa que "marcar a alguien para que escarmiente de tal forma que le sirve de guía sobre cómo obrar en lo sucesivo". Quería hablar de las formas que tengo para conjurarlos: el Juego, el erotismo, la seducción.

Quería hablar de mi hastío causado por aquellos que "revolucionariamente" en lucha contra lo que ellos llaman una "enseñanza escolástica" hablan de una "enseñanza laica" (olvidando que la escolástica es la ocupación propia de un hombre libre y que laico significaba aquel que no sabía leer). Pero no tengo tiempo, o mejor, el tiempo que tengo lo quiero perder jugando con aquellos tres.

Aprendí a desconfiar de la palabra Rendimiento como ya antes desconfiaba de las palabras "desarrollo humano". Aprendí que me encanta hablar de las cosas que no sé. Aprendí que el Miedo también es mi pasión. Aprendí que mis amigos profesores del Seminario en que desde hace un año estamos metidos, tenían razón al señalar que debíamos jugar a estudiar las palabras Cuerpo. Juego. Enseñanza. Aprendí a agradecerles que jueguen conmigo. Pero, por ahora, tengo que llevarle su atún a Hobbes. En otra ocasión jugaremos a decir que frente a los graves que hablan de Rendimiento Académico y Desarrollo Humano nosotros oponemos el Juego y la Seducción, pero eso será cuando hayamos jugado en el seminario a ello. 